\title{
Análise crítica e ajuste de modelos de previsão de fadiga com análise incremental de danos para BGTC executada em pavimento asfáltico semirrígido
}

\author{
Fernando Silva Albuquerque ${ }^{1}$, Airton Teles de Mendonça ${ }^{2}$ \\ 1Universidade Federal de Sergipe, São Cristovão, SE, Brasil, albuquerque.f.s@uol.com.br \\ 2Instituto Federal de Educação, Ciência e Tecnologia de Sergipe, SE, Brasil, airtontelesmendonca@yahoo.com.br
}

Recebido:
10 de dezembro de 2015
Aceito para publicação:
07 de junho de 2017
Publicado:
31 de agosto de 2017
Editor de área:
Francisco Thiago Aragão

\section{Palavras-chaves:}

Camadas tratada com cimento.

Previsão de fadiga.

Lei de Miner.

\section{Keywords:}

Cemented-treated layers.

Predicting fatigue.

Miner's rule.

DOI:10.14295/transportes.v25i2.1046

\section{RESUMO}

O dano que gera fadiga em camadas cimentadas é função das características do próprio material, dos diferentes esforços que solicitam a estrutura do pavimento etc. Este conceito é o princípio da análise de dano acumulado, sendo a Lei de Miner uma das formas mais utilizadas para a sua contabilização. Contudo, com o avanço progressivo do dano, a rigidez das camadas do pavimento também reduz. Baseando-se nesses conceitos, realizou-se um estudo para avaliação de cinco modelos de previsão de desempenho para ruptura por fadiga em camada de Base de Brita Graduada Tratada com Cimento (BGTC), que foi monitorada por dois anos na BR-101/SE. Três deles (AASHTO, 2004; BALBO, 1999; PCA, 1984) utilizam a relação da tensão de tração atuante na camada e sua resistência à tração na flexão. Devido à redução da rigidez da camada, detectada a partir dos resultados de retroanálise de bacias deflectométricas realizadas ao longo estudo, a tensão de tração atuante tende a reduzir ao longo do tempo, gerando uma previsão de vida de fadiga crescente e incompatível matematicamente com o desempenho observado. Os dois outros modelos (SAPEM, 2014; AUSTROADS, 2012) utilizam a deformação específica de tração como critério de ruptura. Como ela aumenta com a redução da rigidez da camada, os dois modelos previram o término da vida de fadiga. O modelo da AUSTROADS passou por um tratamento estatístico para ajustar ao desempenho observado no trecho monitorado. 0 modelo do SAPEM não precisou de ajustes para um nível de confiança de $50 \%$. Foram ajustados também modelos para estimativa do módulo elástico da camada de BGTC em função da evolução do dano.

\begin{abstract}
The development of fatigue damage in cemented-treated layers is a function of itself material characteristics, of the different loads acting on the structure etc. This is the cumulative fatigue damage analysis, in which Miner's rule method is one of the most widely performed. However, due the progressive growth of the damage, the stiffness of the pavement layers decrease. Based on these concepts, a study was conducted to assess five performance prediction models for fatigue failure of a cemented-treated layer, which was evaluated for two years in a Brazilian roadway (BR-101/SE). Three of them (AASHTO, 2004; BALBO, 1999; PCA, 1984) perform the estimations by the ratio of tensile stress in the layer and its flexural strength. Due to the decrease of the layer stiffness, detected by back calculations, the tensile stress of the layer also decreases over time, resulting in a fatigue life growing and mathematically incompatible compared to the observed performance. The other models (SAPEM, 2014; AUSTROADS, 2012) take into account the tensile strain as failure criterion. Since the tensile strain increases as the layer stiffness decreases, both models predict fatigue life. The AUSTROADS model was treated statistically to fit to the observed performance in the monitored stretch. The SAPEM model didn't require fits to a reliability level of $50 \%$. Also, models were fitted to estimate the modulus of the cemented-treated layer as a function of the damage growth.
\end{abstract}




\section{INTRODUÇÃO}

Pavimentos asfálticos com grande volume de tráfego podem ser projetados com base ou sub-base estabilizada quimicamente com cimento Portland (denominadas de camadas cimentadas). Esta solução se constitui em uma forma de melhorar o desempenho estrutural do pavimento e de redução de investimento financeiro em longo prazo, caso o desempenho mecânico destes materiais seja conhecido e respeitado.

Alguns fatores contribuem diretamente com o baixo desempenho em uso de bases tratadas com cimento, tais como (CHEN et al., 2008): a granulometria utilizada, especialmente com agregados de grandes dimensões na mistura, que podem causar segregação; contato deficiente entre a camada cimentada e o revestimento asfáltico quando justapostas, permitindo o acúmulo de água em sua interface; e baixas espessuras de revestimento asfáltico. Chakrabarti e Kodikara (2003) comentam também que o aumento no teor de cimento provoca maior retração da camada durante a hidratação. Um fator importante para a melhora no desempenho geral da estrutura do pavimento é a execução de camadas antirreflexão de trincas entre camadas cimentadas e o revestimento asfáltico, evitando assim o trincamento prematuro do revestimento e a ação da água no pavimento (DJAKFAR e ROBERTS, 1999).

A definição de parâmetros que permitem a previsão de desempenho estrutural de bases cimentadas, talvez seja o item de maior complexidade para a definição de critérios para projetos, já que os danos ocorridos a essas camadas são detectados de forma indireta, pois os defeitos não ficam visíveis à medida que ocorrem como o que acontece na superfície de revestimentos.

Guthrie et al. (2009) estudaram alguns modelos que utilizam tensões ou deformações de tração como critério de ruptura na previsão de fadiga em bases cimentadas. Simularam 90 configurações diferentes de pavimentos, detectando grande variabilidade nas previsões. Entre os modelos estudados, afirmam que o modelo australiano está entre os mais sensíveis às mudanças de características dos materiais, devido ao fato de conter o módulo elástico da camada como requisito para cálculo. 0 modelo da República Sulafricana era pouco sensível às características mecânicas dos materiais e tinham uma tendência a prever menor vida de fadiga que os demais.

Alguns modelos de previsão de desempenho estrutural de bases cimentadas foram propostos em vários métodos de dimensionamento de pavimentos, tais como o da American Association of State Highway and Transportation Officials (AASHTO, 2004), da Portland Cement Association (PCA, 1984), do South African Mechanistic Design Method (SAPEM, 2014) etc. Alguns destes modelos foram estabelecidos com maior ou menor amostragem para validação em campo, mas nenhum deles com análise incremental de danos.

Neste trabalho propôs-se a análise crítica de modelos mecanístico-empíricos de previsão de desempenho estrutural para camada cimentada do tipo BGTC, existente em alguns métodos de dimensionamento ou derivados de pesquisa científica. Utilizaram-se os dados de um trecho monitorado de pavimento asfáltico semirrígido localizado na BR-101/SE, confrontando o desempenho previsto ao real desempenho medido em campo. Além desta análise, propôs-se o ajuste preliminar dos modelos estudados para o critério de ruptura por fadiga, utilizando a análise incremental de danos.

\section{ABORDAGEM MECANICISTA PARA ANÁLISE DE CAMADAS CIMENTADAS}

A identificação da ruptura por fadiga de camadas cimentadas não é algo simples quando estas fazem parte da estrutura de pavimentos asfálticos. Quando em contato direto com misturas asfáticas, a ruptura por fadiga da camada cimentada gera fissuras que geralmente são refletidas para a camada sobrejacente, contudo pode-se levar algum tempo para isto ocorrer, ou mesmo ser confundida com um trincamento originado pela fadiga da própria camada asfáltica. Outra situação que pode ocorrer é a existência de camada intermediária entre a mistura asfáltica e a camada cimentada, o que inibe ou anula a reflexão de trincas para a primeira, impossibilitando a identificação visual na superfície. Nesta última situação, a redução da rigidez da camada cimentada por uma possível ruptura por fadiga, certamente pode colocar 
a camada de mistura asfáltica sob um estado de tensões mais elevado do que aquele pelo qual foi projetada, elevando a possibilidade de dano por fadiga na mesma (SAPEM, 2014; AASHTO, 2004).

O projeto de pavimentos com bases cimentadas no Brasil utiliza o critério da resistência, estabelecido na norma de dimensionamento do Método de Projeto de Pavimentos Flexíveis (DNER, 1981). Este critério é o Índice de Suporte Califórnia (CBR) das camadas granulares e o Coeficiente de Equivalência Estrutural (k), onde este último, no caso de camadas cimentadas, varia com o valor de Resistência à Compressão Simples (RCS).

Nesta mesma publicação (DNER, 1981), diz-se que o comportamento estrutural das camadas cimentadas, em termos do valor do coeficiente $\mathrm{k}$, é tão melhor quanto maior o valor de RCS. Contudo, segundo diferentes métodos de projeto de pavimentos em outros países (SAPEM, 2014; AASHTO, 2004; AUSTROADS, 2012; PCA, 1984) as camadas cimentadas são susceptíveis à rápida ruptura por fadiga, e quanto mais rígido for o material, maiores as tensões internas na camada, o que pode acelerar os processos de trincamento por retração e fadiga (HUANG, 2004; YODER et al., 1975).

A AASHTO (2004) aplica um modelo mecanístico-empírico para previsão de fadiga em bases cimentadas, embora ainda sem calibração adequada para a época desta publicação. Os esforços para calibração foram atribuídos às agências de transportes de cada estado dos EUA. Esta análise realiza também uma sub-rotina de cálculo através de software, com ciclos predefinidos de 2 a 4 semanas, para cálculo do decréscimo do módulo elástico da camada cimentada ao longo do tempo, até atingir o dano atribuído à camada pelo projetista (análise de dano acumulado). 0 modelo mecanístico-empírico utilizado calcula o número de repetições de cada carregamento que solicitará a via, necessário para atingir a ruptura por fadiga, da seguinte forma:

$$
\log N_{f}=\frac{0,972 \beta_{c 1}-\left(\frac{\sigma_{t}}{R_{T, f}}\right)}{0,0825 \beta_{c 2}}
$$

em que $N_{f}$ : número de repetições de eixo para a ruptura por fadiga em camadas cimentadas;

$\sigma_{t}$ : tensão máxima de tração na camada cimentada [MPa];

$R_{T, f}:$ resistência à tração na flexão (módulo de ruptura aos 28 dias) [MPa]; e

$\beta_{c 1}, \beta_{c 2}, \beta_{c 3}$ e $\beta_{c 4}$ : fatores de calibração (SCULLION et al., 2007).

A Portland Cement Association (PCA) também utiliza a relação entre a tensão máxima de tração na base da camada cimentada e a resistência à tração na flexão para o modelo mecanístico-empírico incluso no programa Cement-Treated Base (CTB) (PCA, 1984):

$$
N_{f}=\left(\frac{\beta_{c 4}}{\frac{\sigma_{t}}{R_{T, f}}}\right)^{\beta_{c 3} \cdot 20}
$$

Conforme os modelos anteriores, realizou-se no Brasil um estudo para estabelecer um modelo de previsão de desempenho para BGTC, quando aplicada em pavimentos semirrígidos, em função da relação entre a tensão máxima de tração na base da camada cimentada (no início de sua vida de serviço) e a resistência à tração na flexão (BALBO, 1993):

$$
\log N_{f}=\frac{0,871-\left(\frac{\sigma_{t}}{R_{T, f}}\right)}{0,054}
$$


Cabe salientar que o modelo de previsão de desempenho de Balbo (1993) foi desenvolvido a partir de extenso estudo com ensaios de fadiga em laboratório, mas que ainda não foi definida função de transferência para a sua utilização em previsões de vida de fadiga da BGTC em campo. Contudo, o mesmo modelo foi incluído nos estudos para avaliar a sua sensibilidade em previsões a partir do acúmulo de danos ao longo do tempo.

Alguns estudos definem como critério de ruptura por fadiga, em camadas cimentadas para pavimentos, a deformação específica de tração na fibra inferior da camada prevista para o período de análise. Na Austrália, um modelo de previsão de desempenho adaptado de NAASRA (1987) e utilizado no método australiano de dimensionamento mecanístico-empírico é assim definido (AUSTROADS, 2012):

$$
N_{f}=R F \cdot\left(\frac{11264 / E^{0,804}+190,7}{\varepsilon_{t}}\right)^{12}
$$

em que $E$ : módulo elástico (flexural) do material cimentado [MPa];

$\varepsilon_{t}$ : deformação específica de tração na fibra inferior da camada [microstrain];

$R F$ : fator relacionado ao nível de confiança para a fadiga de materiais cimentados (JAMESON, 2014).

O Método de Dimensionamento Mecanístico-Empírico de Pavimentos da República Sulafricana também utiliza o critério da deformação de tração na fibra inferior da camada, prevista para o período de análise (SAPEM, 2014). Além do critério de fadiga, faz-se uso também do critério de esmagamento da camada causado pela tensão vertical no seu topo (não é escopo deste trabalho), o que remete à necessidade de limitar a magnitude das tensões verticais na camada a um percentual da RCS.

Para o critério de fadiga, o modelo de previsão de desempenho estabelece o dano como o número de repetições de carga que a camada suportará, para uma razão da deformação de tração prevista e a deformação de ruptura da camada, de acordo com a sua rigidez (SAPEM, 2014):

$$
N_{f}=S F \cdot 10^{c\left(1-\frac{\varepsilon_{t}}{d \cdot \varepsilon_{b}}\right)}
$$

em que $S F=$ fator de correção para propagação da trinca em função da espessura da camada (SAPEM, 2014);

$\varepsilon_{b}=$ deformação de ruptura por tração [microstrain] (sugestões em SAPEM, 2014);

$c ; d=$ coeficientes do modelo (SAPEM, 2014).

\section{TRECHO ANALISADO}

O Trecho Monitorado era um pavimento asfáltico novo, em segmento plano e com boa drenagem. Foi escolhido de forma que o tráfego e as condições climáticas fossem representativos da região litorânea do Estado de Sergipe. 0 trecho tem extensão de 280 m e situa-se na BR-101/SE, no município de São Cristóvão, região metropolitana de Aracaju.

0 projeto do trecho monitorado foi de responsabilidade do DNIT e empregou o Método de Projeto de Pavimentos Flexíveis (DNER, 1981) e o método da resiliência, preconizado pelo DNER-PRO 269/94 (DNER, 1994), para o cálculo da espessura mínima de revestimento asfáltico.

0 resultado do projeto indicou um pavimento com base de Brita Graduada Tratada com Cimento (BGTC), na faixa II do DER/PR, com adição de 3\% de cimento e resistência mínima à compressão de 3,5 MPa. $O$ revestimento asfáltico foi dividido em uma camada de transição de BINDER, com 7,5 cm de es- 
pessura, e uma mistura asfáltica com ligante modificado com polímero SBS, com 5,0 cm de espessura, servindo como camada de rolamento. Ainda, existe uma camada de sub-base de 15,0 cm de solo natural sobre o subleito (Figura 1).

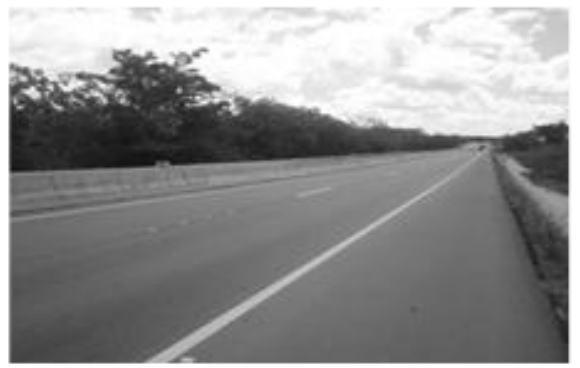

(a)

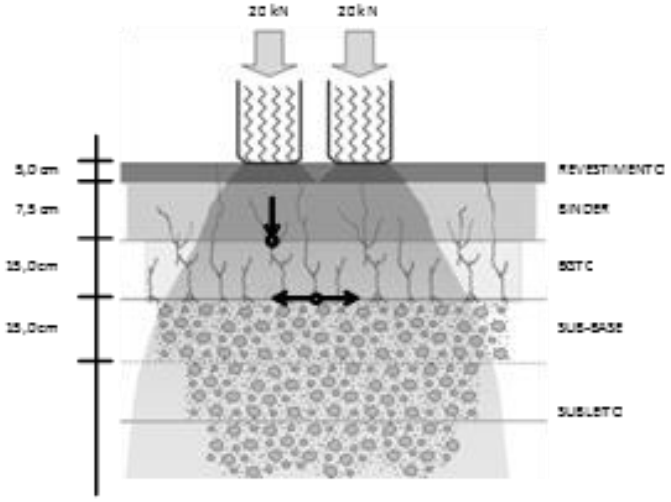

(b)

Figura 1: (a) vista e (b) camadas do pavimento do Trecho Monitorado

Logo após a conclusão dos serviços de execução e antes da liberação do trecho monitorado ao tráfego, foi realizada em laboratório a caracterização mecânica dos materiais empregados em suas camadas. Foram colhidas amostras representativas do subleito e da camada de sub-base, ambas extraídas de trincheiras na pista de rolamento do pavimento. As mesmas foram levadas a laboratório para ensaios de módulo de resiliência pela norma DNIT 134/2010-ME, cada amostra com três exemplares. Para as misturas asfálticas foram retirados seis exemplares (CPs) através de sondas rotativas. Os materiais foram coletados e levados ao Laboratório de Geotecnia e Pavimentação da UFS, onde foram preparados e realizados os ensaios de Módulo de Resiliência, pela norma DNIT 135/2010-ME, e Resistência à Tração, pela norma DNER-ME 138/94. Para a obtenção do Módulo de Resiliência da camada de BGTC foi empregado o ensaio triaxial de carga repetida, padronizado no Brasil pela norma DNIT 134/2010-ME. Da mistura foram obtidos três corpos de prova cilíndricos compactados na energia do Proctor modificado e curadas por 28 dias, todas moldadas em laboratório, já que a retirada de amostras da pista se mostrou inviável, devido às rupturas dos CPs durante o processo. As tensões desvios aplicadas durante o ensaio foram de magnitudes inferiores a 35\% da resistência à compressão simples e as deformações foram obtidas com LVDTs instalados no terço médio dos corpos de prova. Adicionalmente, foram realizados ensaios de Resistência à Compressão Simples, pela norma NBR 5739/2007, e Resistência à Tração, pela norma DNERME 138/94, cada um com três exemplares. As características mecânicas obtidas em laboratório para as camadas do Trecho Monitorado estão apresentadas na Tabela 1.

Tabela 1: Resultados de ensaios mecânicos com materiais do trecho monitorado

\begin{tabular}{|c|c|c|c|c|}
\hline \multicolumn{5}{|c|}{ Misturas Asfálticas } \\
\hline & Módulo Resiliente (MPa) & \multicolumn{2}{|c|}{$\begin{array}{l}\text { Resistência à Tração } \\
\text { (MPa) }\end{array}$} & $\mathrm{MR} / \mathrm{RT}$ \\
\hline $\begin{array}{c}\text { Revestimento (CAP modificado } \\
\text { com SBS) }\end{array}$ & 4.273 & \multicolumn{2}{|r|}{1,49} & 2.864 \\
\hline \multirow[t]{3}{*}{ BINDER } & 9.309 & \multicolumn{2}{|r|}{2,03} & 4.583 \\
\hline & \multicolumn{3}{|c|}{ Materiais Cimentados e Solos } & \\
\hline & Módulo Resiliente (MPa) & $\mathrm{R}^{2}$ & $\begin{array}{l}\text { Resistência à Tração } \\
\text { (MPa) }\end{array}$ & $\begin{array}{c}\text { Resistência à } \\
\text { Compressão } \\
\text { (MPa) }\end{array}$ \\
\hline BGTC & (1) $M R_{B G T C}=27282,0\left(\sigma_{d}\right)^{0,8938}$ & 0,99 & 0,672 & 4,5 \\
\hline Sub-base de Solo & (2) $M R_{S B}=620,0(\theta)^{-0,181}$ & 0,61 & - & - \\
\hline Subleito & $\begin{array}{l}\text { (2) } M R_{\text {SUBLEITO }}= \\
415,0(\theta)^{-0,267}\end{array}$ & 0,70 & - & - \\
\hline
\end{tabular}

(1) $\sigma_{d}$ : tensão desvio; (2) $\theta$ : somatório de tensões. 
0 perfil e volume inicial do tráfego foram obtidos com base em contagem realizada pelo DNIT logo após a execução dos serviços de duplicação da BR-101/SE, em maio de 2012. A taxa de crescimento do tráfego em um período de 2 anos de pesquisa (fevereiro de 2012 a janeiro de 2014) foi obtida pelos registros mensais de contagem de tráfego realizada por radares instalados na rodovia, próximos ao segmento em análise. A taxa de crescimento anual para o tráfego misto foi de 12,25\% e, especificamente para os veículos comerciais, de 31,53\%. Foi possível também determinar a taxa de ocupação de faixa, na qual a faixa da direita comportou cerca de $80 \%$ dos veículos comerciais. Uma pesquisa de pesagem de cargas de tráfego foi realizada simultaneamente à contagem, o que tornou possível avaliar os efeitos dos carregamentos de acordo com quatro estratos regulares de frequência, delimitados pelos quartis das distribuições. Os histogramas de frequências de cargas por tipo de eixo veicular e a projeção do número acumulado de passagens por cada tipo de eixo de carga (sem uso de fatores de equivalência de carga) que solicitou a rodovia durante o período do estudo estão apresentados nas Figuras 2 e 3, respectivamente. Os eixos de carga levados em consideração e suas respectivas cargas foram:

- 1ESRS: eixo simples com rodagem singela, com médias de cargas de eixo de $3.367 \mathrm{~kg}, 4.593 \mathrm{~kg}, 5.113$ $\mathrm{kg}$ e $6.788 \mathrm{~kg}$, para cada um dos quatro estratos da distribuição;

- 2ESRS: eixo duplo direcional com rodagem singela, com médias de cargas de eixo de $9.980 \mathrm{~kg}, 11.730$ $\mathrm{kg}, 12.580 \mathrm{~kg}$ e $16.090 \mathrm{~kg}$, para cada um dos quatro estratos da distribuição;

- ESRD: eixo simples com rodagem dupla, com médias de cargas de eixo de $3.933 \mathrm{~kg}, 6.237 \mathrm{~kg}, 7.699$ $\mathrm{kg}$ e $11.741 \mathrm{~kg}$, para cada um dos quatro estratos da distribuição;

- ETD: eixo tandem duplo, com médias de cargas de eixo de $7.621 \mathrm{~kg}, 12.956 \mathrm{~kg}, 15.569 \mathrm{~kg}$ e 20.528 $\mathrm{kg}$, para cada um dos quatro estratos da distribuição;

- ETT: eixo tandem triplo, com médias de cargas de eixo de $11.448 \mathrm{~kg}, 19.766 \mathrm{~kg}, 23.114 \mathrm{~kg}$ e 29.355 $\mathrm{kg}$, para cada um dos quatro estratos da distribuição.

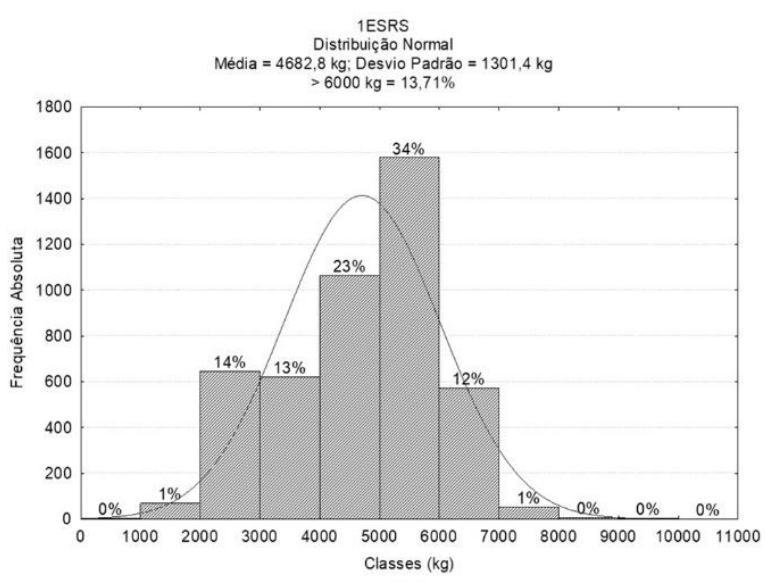

(a)
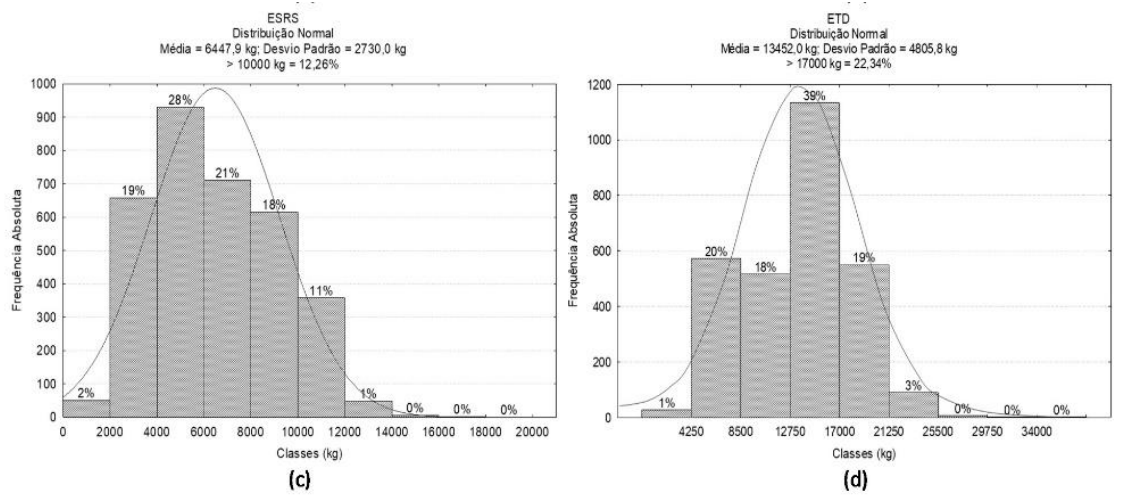

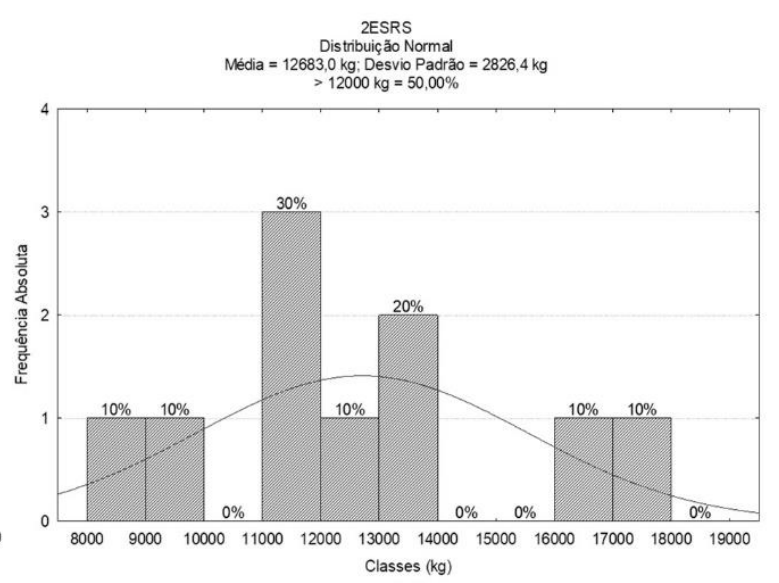

(b)

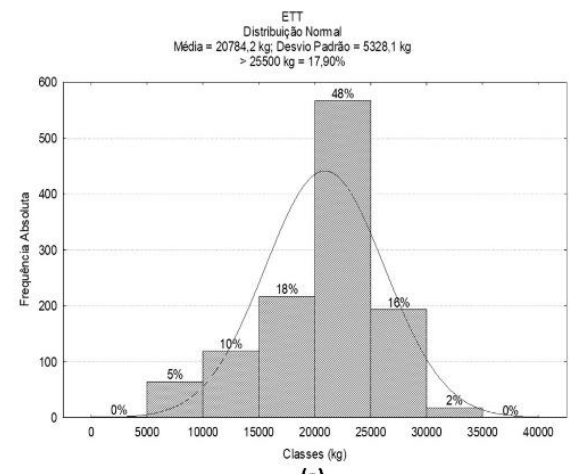

(e)

Figura 2. Histogramas de frequência de cargas por eixo veicular no Trecho Monitorado:

(a) 1ESRS; (b) 2ESRS; (c) ESRD; (d) ETD; e (e) ETT 


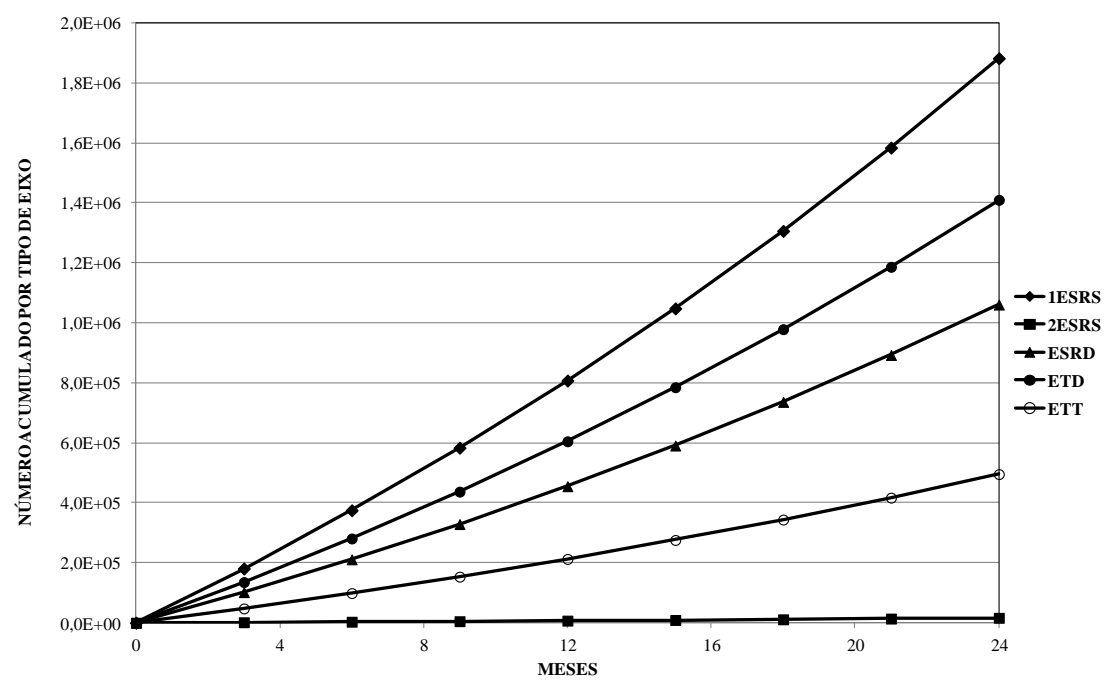

Figura 3. Número acumulado por tipo de eixo de carga para o Trecho Monitorado

\section{MÉTODOS DE TRABALHO}

Nesta pesquisa foi utilizado o software AEMC (Análise Elástica de Múltiplas Camadas), módulo do sistema SISPAV (FRANCO, 2007), para os procedimentos de análise estrutural e retroanálises das bacias deflectométricas levantadas através dos equipamentos Falling Weight Deflectometer (FWD) e Viga Benkelman.

O AEMC é um programa específico para o cálculo de tensões, deformações e deslocamentos, com rotinas para entrada de dados e apresentação de resultados. 0 programa processa os cálculos com base no programa JULEA através de uma sub-rotina (FRANCO, 2007).

Nas análises da estrutura resultante do projeto do DNIT, agora utilizando procedimentos da mecânica dos pavimentos, foram calculadas as tensões e as deformações específicas de tração na fibra inferior da camada de BGTC para a análise de dano por fadiga. Estes resultados foram obtidos para a situação inicial do pavimento, cujo estado estrutural era de total integridade das camadas, utilizando os resultados dos módulos de resiliência das camadas obtidos em laboratório, e para mudanças nas condições mecânicas do pavimento a cada 03 meses, de acordo com a evolução de danos. Como não era objetivo deste trabalho, tensões e deformações em camadas asfálticas e de solos não foram aqui discutidas.

Para avaliar a evolução do comportamento estrutural do trecho monitorado, foi realizado um total de cinco monitoramentos de bacias deflectométricas ao longo de dois anos, sendo o primeiro realizado com Viga Benkelman no topo da BGTC (28 dias após a sua execução e 03 meses antes da entrega do pavimento ao tráfego) e as demais no topo da camada de revestimento (já após a liberação do pavimento ao tráfego), sendo um com equipamento FWD e as demais com Viga Benkelman. Os valores das deflexões medidas foram corrigidos de acordo com as temperaturas do revestimento durante o ensaio, através do modelo de Park e Kim (1997), para uma temperatura padronizada de 25ㄷ:

$$
W_{t o}=10^{-n(t-t o)} \cdot W_{t}
$$

em que $n=5,807 \times 10^{-6}\left(h_{a c}\right)^{1,4635}$ ao longo da trilha de roda; ou

$n=6,560 \times 10^{-6}\left(h_{a c}\right)^{1,4241}$ ao longo do centro da faixa de rolamento;

$h_{a c}$ : espessura da camada de concreto asfáltico [mm];

$W_{t 0}$ : deflexão corrigida $\left[x 10^{-2} \mathrm{~mm}\right]$ para a temperatura $t_{0}\left[{ }^{\circ} \mathrm{C}\right]$ de referência;

$W_{t}$ : deflexão medida $\left[x 10^{-2} \mathrm{~mm}\right]$ na temperatura $t\left[{ }^{\circ} \mathrm{C}\right]$ do ensaio. 
A iteração do processo de retroanálise foi realizada de forma manual, atribuindo valores de módulos elásticos para as camadas, visando o ajustamento entre as linhas de influência teórica e de campo. 0 procedimento de ajuste das linhas de influência foi realizado até que o resultado da raiz dos erros médios quadráticos percentuais entre deflexões da bacia teórica e de campo fosse menor que $5 \%$. Os resultados de cinco monitoramentos realizados no período estão na Tabela 2, contendo o tratamento estatístico dos mesmos, que permitiu a observação indireta dos danos estruturais às camadas dos pavimentos. Desta forma, pode-se observar a evolução temporal dos módulos de resiliência das camadas a partir da condição de total integridade até dois anos do pavimento em serviço (Figura 4). Na condição de total integridade foram utilizados os resultados de módulos de resiliência obtidos em laboratório. Isto foi devido à constatação de deflexões máximas semelhantes quando analisando pelo AEMC a estrutura do pavimento, conforme estava após 28 dias de execução da BGTC, com os módulos de resiliência retroanalisados da Tabela 2 ou utilizando os modelos da Tabela 1.

A dispersão dos resultados de módulos de resiliência das camadas de revestimento, BINDER e BGTC foi relativamente baixa até o quarto monitoramento. No último monitoramento, quando já tinha acontecido a provável ruptura da camada de BGTC, todos os coeficientes de variação superaram $15 \%$. As condições mecânicas da sub-base e subleito variaram bastante, mesmo se tratando de materiais homogêneos em todo o trecho monitorado. Possivelmente, as condições de umidade podem ter variado ao longo do trecho monitorado, o que modifica sensivelmente o comportamento mecânico das camadas granulares.

Tabela 2: Módulos resilientes das camadas retroanalisados de bacias deflectométricas

\begin{tabular}{|c|c|c|c|c|c|c|c|c|}
\hline Mês & Estatística & $\mathrm{REV}_{\mathrm{SBS}}$ & BINDER & BGTC & SUB-BASE & SUBLEITO & REMQ\% & QUANT. \\
\hline & $\overline{M R}$ (MPa) & - & - & 5050 & 503 & 411 & & \\
\hline \multirow{6}{*}{$\begin{array}{l}3 \text { meses an- } \\
\text { tes da aber- } \\
\text { tura }\end{array}$} & $\delta(\mathrm{MPa})$ & - & - & 749 & 151 & 168 & & \\
\hline & CV (\%) & - & - & 14,83 & 30,02 & 40,88 & 2,2 & 13 \\
\hline & $M R_{\text {máx }}(\mathrm{MPa})$ & - & - & 6000 & 650 & 600 & & \\
\hline & $M R_{\min }(\mathrm{MPa})$ & - & - & 4500 & 400 & 350 & & \\
\hline & $\overline{M R}(\mathrm{MPa})$ & 4200 & 8571 & 4571 & 614 & 529 & & \\
\hline & $\delta(\mathrm{MPa})$ & 0 & 189 & 189 & 69 & 70 & & \\
\hline \multirow[t]{5}{*}{2} & CV (\%) & 0,00 & 2,20 & 4,13 & 11,23 & 13,22 & 0,6 & 7 \\
\hline & $M R_{\text {máx }}(\mathrm{MPa})$ & 4200 & 9000 & 5000 & 700 & 650 & & \\
\hline & $M R_{m i n}(\mathrm{MPa})$ & 4200 & 8500 & 4500 & 500 & 450 & & \\
\hline & $\overline{M R}(\mathrm{MPa})$ & 3300 & 4000 & 1083 & 233 & 219 & & \\
\hline & $\delta(\mathrm{MPa})$ & 0 & 0 & 41 & 75 & 144 & & \\
\hline \multirow[t]{5}{*}{13} & CV (\%) & 0,00 & 0,00 & 3,77 & 32,26 & 65,89 & 3,1 & 6 \\
\hline & $M R_{\text {máx }}(\mathrm{MPa})$ & 3300 & 4000 & 1100 & 350 & 450 & & \\
\hline & $M R_{\text {mín }}(\mathrm{MPa})$ & 3300 & 4000 & 1000 & 150 & 100 & & \\
\hline & $\overline{M R}(\mathrm{MPa})$ & 3277 & 3885 & 981 & 237 & 230 & & \\
\hline & $\delta(\mathrm{MPa})$ & 83 & 416 & 75 & 51 & 72 & & \\
\hline \multirow[t]{5}{*}{20} & CV (\%) & 2,54 & 10,71 & 7,66 & 21,48 & 31,21 & 3,2 & 13 \\
\hline & $M R_{\text {máx }}(\mathrm{MPa})$ & 3300 & 4000 & 1100 & 300 & 280 & & \\
\hline & $M R_{\min }(\mathrm{MPa})$ & 3000 & 2500 & 800 & 100 & 80 & & \\
\hline & $\overline{M R}(\mathrm{MPa})$ & 3069 & 3392 & 785 & 254 & 290 & & \\
\hline & $\delta(\mathrm{MPa})$ & 343 & 675 & 195 & 81 & 139 & & \\
\hline \multirow[t]{3}{*}{24} & CV (\%) & 11,16 & 19,90 & 24,87 & 31,78 & 48,01 & 2,5 & 13 \\
\hline & $M R_{m a ́ x}(\mathrm{MPa})$ & 3300 & 4000 & 1000 & 350 & 450 & & \\
\hline & $M R_{\min }(\mathrm{MPa})$ & 2500 & 2500 & 500 & 150 & 100 & & \\
\hline
\end{tabular}

OBS.: - REMQ\%: raiz do erro médio quadrático percentual.

- CV: coeficiente de variação.

- QUANT: quantidade de bacias deflectométricas avaliadas.

Observando-se a Figura 4, o comportamento da camada de Binder foi governado pelo da BGTC, provavelmente devido ao contato direto existente entre essas duas camadas, o que proporciona uma rápida reflexão de trincas. 
A identificação da ruptura por fadiga da base cimentada foi determinada de acordo com a análise do módulo elástico remanescente. Segundo Theyse et al. (1996), uma base de material cimentado com RCS (Resistência à Compressão Simples) de 4,5 MPa é classificada como um material do tipo C2 para o método de projeto mecanístico da República Sulafricana, na qual a ruptura por fadiga é atingida quando o módulo de elasticidade encontra-se entre $500 \mathrm{MPa}$ e $800 \mathrm{MPa}$. Este intervalo foi adotado para a identificação do momento em que houve a ruptura por fadiga da BGTC em campo. Isto possibilitou comparar o comportamento de campo (relacionada a ruptura por fadiga) com o comportamento previsto pelos modelos de previsão de desempenho testados neste trabalho. Para isto foram analisados os modelos de dano por fadiga australiano (AUSTROADS, 2012), norte americano (AASHTO, 2004), da PCA (1984), de Balbo (1993) e da república da sulafricana (SAPEM, 2014), aplicando a Lei de Miner para a análise linear de dano para ciclos de 03 meses. Cabe ressaltar que o modelo de Balbo (1993), embora desenvolvido em nível laboratorial, o que requer calibração em campo, foi utilizado neste estudo para prever a fadiga da camada de BGTC em campo ao longo do tempo. 0 objetivo foi avaliar a sensibilidade de modelos de previsão de ruptura por fadiga baseados na tensão de tração, mas utilizando o princípio da Lei de Miner e considerando a redução de rigidez da camada com o acúmulo de danos.

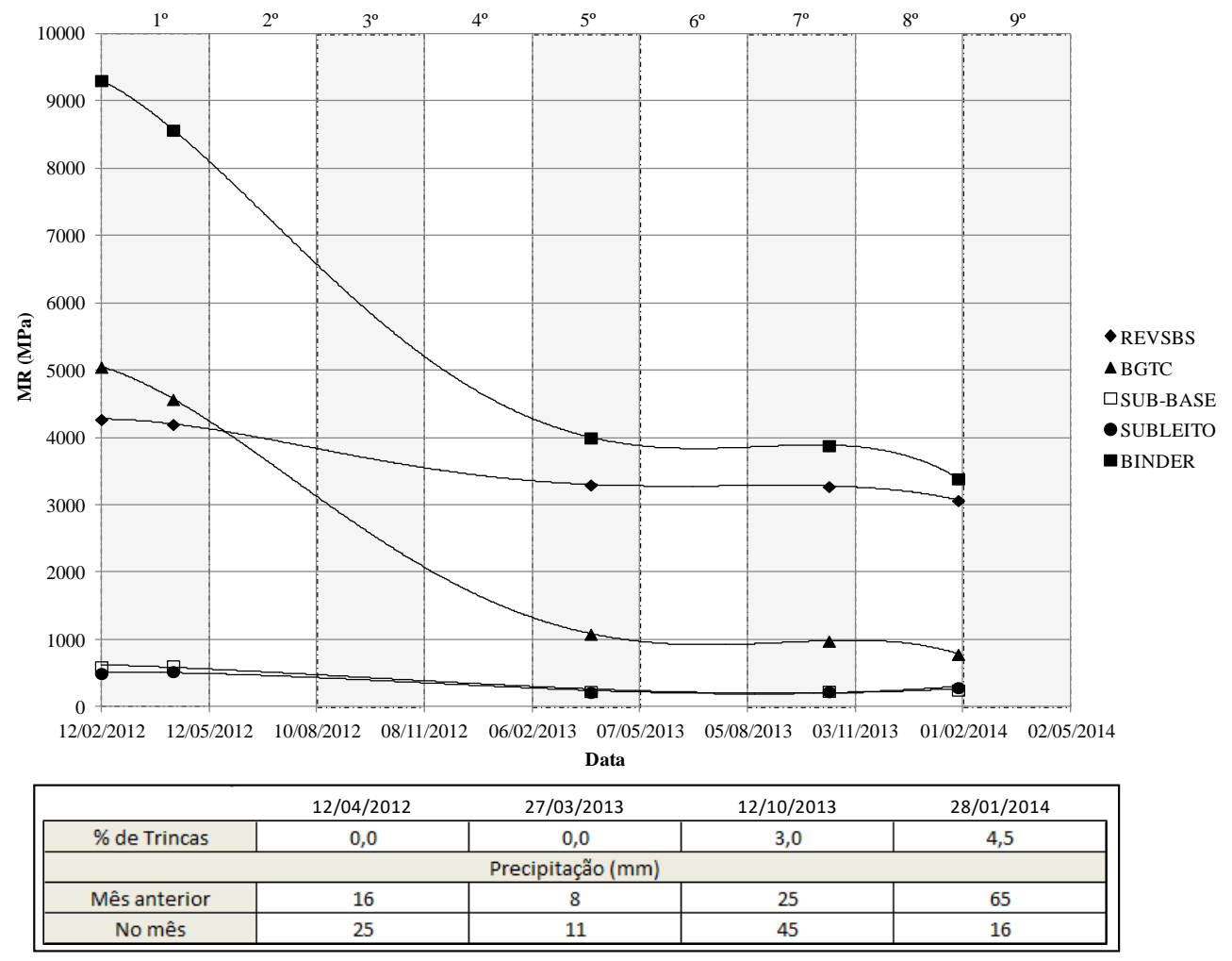

Figura 4. Evolução Temporal dos Módulos de Resiliência no trecho monitorado

A Lei de Miner utiliza o princípio de análise do dano causado por tensões oriundas de carregamentos de amplitudes variáveis. Neste trabalho, tais carregamentos foram classificados por tipo de eixo e magnitudes de cargas que solicitaram a via no período, utilizando quatro estratos regulares de frequência, delimitados pelos quartis das distribuições de carga de cada eixo rodoviário. Como cada eixo de carga possui configuração geométrica e cargas distintas uns dos outros, o dano $(D)$ causado pelo conjunto do tráfego é contabilizado individualmente da seguinte forma:

$$
D=\sum_{i=0}^{k} D_{i}
$$


em que $\quad D_{i}=n_{i} / N_{i}$ refere-se ao dano causado por um nível de tensão $\sigma_{i}$;

$n_{i}$ : número de ciclos em serviço no nível de tensão $\sigma_{i}$;

$N_{i}$ : número de ciclos que levaria o material à ruptura no nível de tensão $\sigma_{i}$.

Como os modelos da AASHTO (2004), Balbo (1993) e da PCA (1984) utilizam o critério do módulo de rigidez (resistência à tração na flexão), foi utilizada a relação deste com a resistência à tração indireta proposta pela AUSTROADS (2008). Neste estudo, com o objetivo de definir protocolos de ensaios de laboratório para materiais cimentados, foram realizados ensaios em 12 materiais com 3 e $4 \%$ de cimento, concluindo-se que a resistência à tração na flexão era $40 \%$ superior à resistência à tração indireta.

Complementarmente, realizou-se um estudo paramétrico para estabelecer um ajuste, para as condições observadas em campo, dos modelos de previsão de desempenho com critério de ruptura pela deformação específica de tração. Vale ressaltar que este ajuste levou em consideração a análise de danos acumulados para ciclos de 03 meses de análise e a partir de características estruturais variáveis ao longo de cada ciclo.

\section{RESULTADOS E DISCUSSÕES}

\subsection{Ruptura por Fadiga na BGTC}

Com base na avaliação mecanicista da estrutura projetada para o trecho monitorado, observou-se que a base de BGTC governou o desempenho estrutural do pavimento em análise. Contudo, a identificação do momento aproximado em que ocorreu a ruptura por fadiga em campo não é uma questão simples, pois, como os trincamentos serão iniciados em uma camada subjacente ao revestimento asfáltico (na BGTC), a identificação visual de trincas no topo do revestimento representa uma consequência da reflexão de trincas da BGTC para aquela camada. Portanto, o dano por fadiga ocorre em um momento anterior. A identificação deste momento pode ser feita indiretamente pela análise da magnitude do módulo de resiliência da camada de BGTC obtido por retroanálises de bacias deflectométricas de campo.

Theyse et al. (1996) especifica as faixas de valores dos módulos de resiliência para o material classificado como $\mathrm{C} 2$ em diversas condições de integridade da camada cimentada. Estas condições são divididas em: estágio 1, para uma condição intacta; estágio 2, para a camada com trincamentos por retração, onde este processo finaliza nos primeiros meses depois de executada a camada; estágio 3, para um microtrincamento associado ao tráfego (ruptura por fadiga); e estágio 4, quando a camada já está com ruptura avançada e com comportamento equivalente a uma base granular. Associando os valores de módulos de resiliência retroanalisados para a BGTC (a partir da Figura 4), com as faixas de valores identificadas por Theyse et al. (1996), pode-se definir o momento aproximado da ruptura por fadiga para a camada de BGTC do pavimento do trecho monitorado (Figura 5), quando atinge o estágio 3 do gráfico, cujo módulo de resiliência era de aproximadamente $800 \mathrm{MPa}$, após 21 meses de liberação ao tráfego. Este critério é semelhante ao da AASHTO (2004), que define um módulo de resiliência de aproximadamente $700 \mathrm{MPa}$ para o momento de ruptura por fadiga.

Observa-se ainda que o decaimento no valor do módulo de resiliência ao longo do tempo não é linear, apresentando vários pontos de inflexão que definem os comportamentos e estágios de degradação da BGTC (THEYSE et al., 1996). Contudo, é possível estabelecer dois padrões de evolução do módulo de resiliência em função da ação do tráfego. 0 primeiro acontece um mês após a liberação ao tráfego até a formação de microfissuras (MR aproximadamente $1.300 \mathrm{MPa}$ ), onde o módulo de resiliência reduz a uma taxa mais elevada. 0 segundo a partir da condição anterior até que o trincamento atinja o topo da camada (trincamento avançado - MR aproximadamente $800 \mathrm{MPa}$ ), contudo com módulo de resiliência reduzindo a uma taxa menor. No segundo padrão, apesar de reduções do MR serem inferiores, a variação das deformações específicas de tração é alta, proporcionando nesta fase um maior acúmulo de danos à camada. 


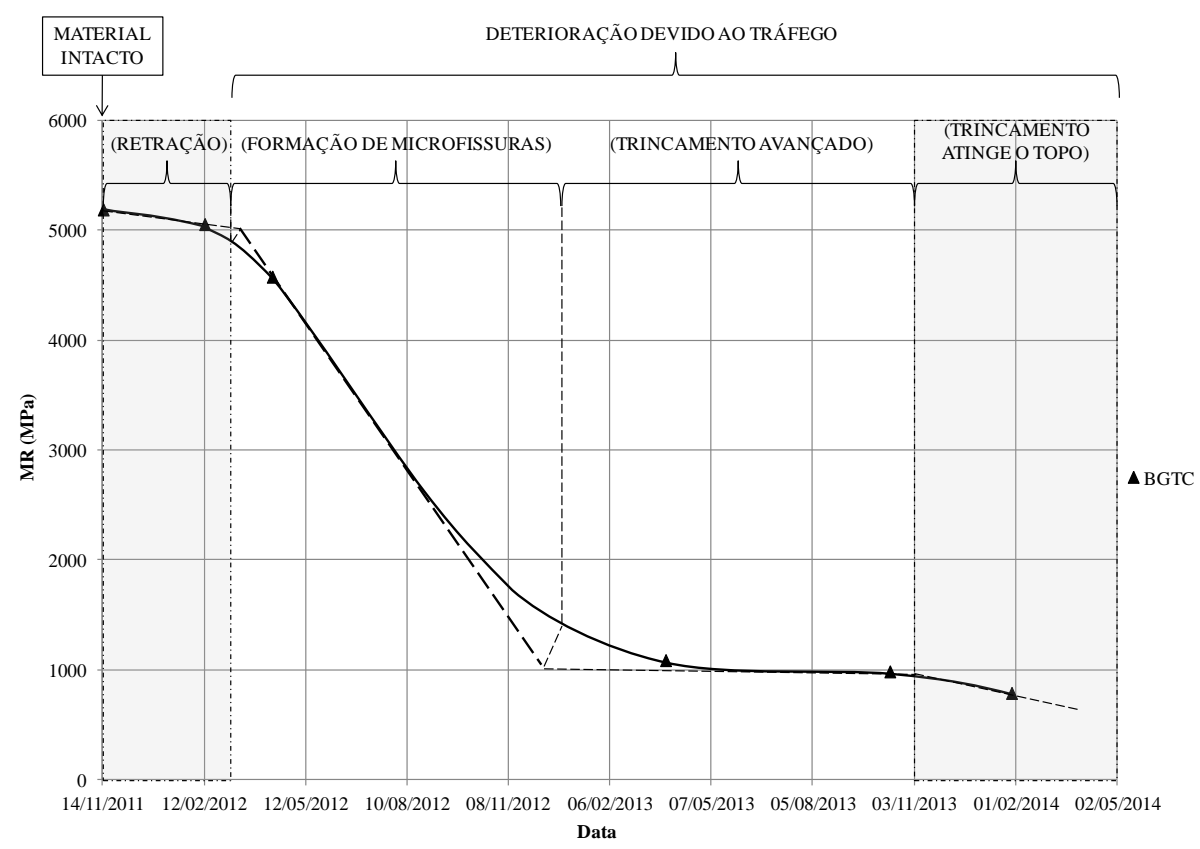

Figure 5. Identificação da ruptura por fadiga no trecho monitorado

\subsection{Avaliação de modelos de previsão de ruptura por fadiga em BGTC}

A avaliação de dano foi efetuada segundo a Lei de Miner para cada um dos modelos abordados neste trabalho. Foram utilizados os carregamentos transmitidos por cada tipo e cargas de eixo que solicita o pavimento, segundo pesquisa e projeção de tráfego realizada. 0 estudo de dano acumulado é apresentado na Tabela 3 de forma resumida por ciclo de análise, já que a análise completa realizada leva em consideração os quatro níveis de carregamento para os cinco tipos de eixo analisados, o que impede a sua apresentação detalhada neste trabalho.

Observa-se na Tabela 3 que o cálculo do dano, levando-se em consideração a redução da rigidez da camada de BGTC para os modelos da AASHTO (2004), Balbo (1993) e da PCA (1984), tende a prever uma vida de fadiga crescente ao longo do tempo. Este fato é incoerente com as observações de campo. Isto deve-se à utilização da tensão de tração como variável independente destes modelos de previsão de vida de fadiga. Como o módulo de resiliência decresce ao longo do tempo, as tensões internas também tendem a reduzir, o que gera um resultado matemático de vida de fadiga indeterminado.

Por outro lado, os modelos que levam em consideração a deformação específica de tração (AUSTROADS, 2012; SAPEM, 2014) detectam a evolução do dano ao longo do tempo. Isto deve-se à redução no módulo de resiliência da BGTC, o que proporciona maior deformação à camada. Certamente o critério da deformação específica de tração é o mais adequado para a análise acumulada de danos, pelo fato dela aumentar ao longo do tempo.

Conforme já observado no item 5.1, a ruptura da camada foi aproximadamente ao final do $21^{\circ}$ mês, quando o módulo de resiliência atingiu $800 \mathrm{MPa}$. Além disso, este foi o período no qual as deformações de tração para todos os tipos de eixo alcançaram ou superaram $120 \times 10^{-6} \mathrm{~m} / \mathrm{m}$, considerada como última para camada cimentada do tipo C2 (SAPEM, 2014).

O modelo de SAPEM (2014) a um nível de confiança de 50\% (semelhante ao utilizado no Brasil para amostragem mínima no controle tecnológico de obras) previu dano por fadiga à BGTC de 99,7\%.

0 modelo da AUSTROADS (2012), também a um nível de confiança de 50\%, previu dano à camada de BGTC muito superior a $100 \%$ no final do $21^{\circ}$ mês. 0 mesmo convergiu a este valor entre o $13^{\circ}$ e $15^{\circ}$ mês, mas com grande crescimento exponencial após esse período. Portanto, observa-se que o mesmo subestimou a vida de fadiga da camada de BGTC do trecho monitorado analisado em aproximadamente $49 \%$ do tráfego total no período de análise. 
Tabela 3: Resumo da análise de dano por fadiga na BGTC a partir de modelos de previsão

\begin{tabular}{|c|c|c|c|c|c|c|c|c|c|c|c|c|c|c|}
\hline \multirow[b]{2}{*}{$\begin{array}{l}\text { 岃 } \\
\stackrel{\text { }}{\Sigma}\end{array}$} & \multirow[b]{2}{*}{ 妏 } & \multirow[b]{2}{*}{ 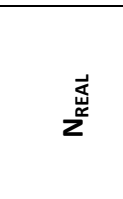 } & \multirow{2}{*}{ 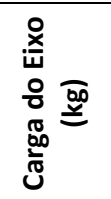 } & \multirow[b]{2}{*}{ 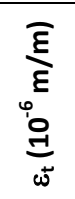 } & \multicolumn{2}{|c|}{ SAPEM $^{(1)}$} & \multicolumn{2}{|c|}{ AUSTROADS $^{(2)}$} & \multicolumn{2}{|c|}{$\mathrm{PCA}^{(3)}$} & \multicolumn{2}{|c|}{ AASHTO $^{(4)}$} & \multicolumn{2}{|c|}{ BALBO $^{(5)}$} \\
\hline & & & & & $\frac{\overline{0}}{\frac{0}{y}}$ & 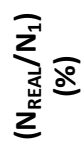 & $z^{N}$ & 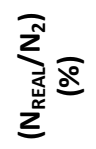 & $z^{m}$ & 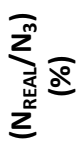 & $z^{+}$ & 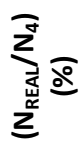 & $z^{n}$ & 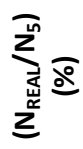 \\
\hline \multirow{5}{*}{$\stackrel{m}{o}$} & 1ESRS & $1,81 \mathrm{E}+0$ & 4965,2 & 33,3 & $207,08,91 \mathrm{E}+06$ & 2,1 & $8,32 E+11$ & 0,0 & $3,10 \mathrm{E}+17$ & 0,0 & $2,68 \mathrm{E}+11$ & 0,0 & $6,60 \mathrm{E}+12$ & 0,0 \\
\hline & 2ESRS & $1,57 E+0$ & 12595,0 & 43,5 & $266,37,46 E+06$ & 0,0 & $5,98 E+09$ & 0,0 & $7,59 \mathrm{E}+13$ & 0,0 & $3,00 E+10$ & 0,0 & $3,01 E+11$ & 0,0 \\
\hline & ESRD & $1,02 E+0$ & 7402,6 & 38,5 & $217,68,32 E+06$ & 1,3 & $2,63 E+12$ & 0,1 & $1,66 E+19$ & 0,0 & $5,35 E+11$ & 0,0 & $1,88 E+13$ & 0,0 \\
\hline & TANDEM 2 & $1,35 E+0$ & 14168,2 & 34,0 & $191,38,87 E+06$ & 1,6 & $1,00 E+13$ & 0,0 & $1,83 E+20$ & 0,0 & $8,08 E+11$ & 0,0 & $3,33 E+13$ & 0,0 \\
\hline & TANDEM3 & $34,76 E+0$ & 20920,7 & 33,5 & $188,38,93 E+06$ & 0,5 & $9,84 \mathrm{E}+12$ & 0,0 & $1,77 E+20$ & 0,0 & $8,01 E+11$ & 0,0 & $3,29 E+13$ & 0,0 \\
\hline \multirow{5}{*}{$\stackrel{\varphi}{i}$} & 1ESRS & $1,94 \mathrm{E}+0$ & 4965,2 & 36,2 & $182,78,48 \mathrm{E}+06$ & 2,3 & $3,35 E+11$ & 0,0 & $4,03 E+18$ & 0,0 & $4,89 E+11$ & 0,0 & $1,46 E+13$ & 0,0 \\
\hline & 2ESRS & $1,69 \mathrm{E}+0$ & 12595,0 & 47,3 & $234,07,00 E+06$ & 0,0 & $2,54 \mathrm{E}+09$ & 0,0 & $1,12 \mathrm{E}+15$ & 0,0 & $7,48 \mathrm{E}+10$ & 0,0 & $1,03 E+12$ & 0,0 \\
\hline & ESRD & $1,09 E+0$ & 7402,6 & 41,5 & $190,27,94 E+06$ & 1,5 & $1,22 E+12$ & 0,3 & $2,63 E+20$ & 0,0 & $9,03 E+11$ & 0,0 & $3,73 E+13$ & 0,0 \\
\hline & TANDEM2 & $2,45 \mathrm{E}+0$ & 14168,2 & 36,8 & $168,68,48 \mathrm{E}+06$ & 1,8 & $4,32 E+12$ & 0,0 & $2,43 E+21$ & 0,0 & $1,26 \mathrm{E}+12$ & 0,0 & $5,92 E+13$ & 0,0 \\
\hline & TANDEM3 & $3,11 E+0$ & 20920,7 & 35,6 & $165,38,63 E+06$ & 0,6 & $5,36 \mathrm{E}+12$ & 0,0 & $2,57 E+21$ & 0,0 & $1,27 E+12$ & 0,0 & $5,97 E+13$ & 0,0 \\
\hline \multirow{5}{*}{ 啇 } & 1ESRS & $2,09 \mathrm{E}+0$ & 4965,2 & 43,6 & $160,37,51 \mathrm{E}+06$ & 2,9 & $4,83 E+10$ & 0,1 & $5,59 E+19$ & 0,0 & 11 & 0,0 & -13 & 0,0 \\
\hline & 2ESRS & $1,81 E+0$ & 12595,0 & 56,8 & $205,05,97 E+06$ & 0,0 & $3,61 E+08$ & 0,0 & $1,71 \mathrm{E}+16$ & 0,0 & $1,70 E+11$ & 0,0 & $3,10 E+12$ & 0,0 \\
\hline & ESRD & $1,18 \mathrm{E}+0$ & 7402,6 & 49,5 & $165,57,02 E+06$ & 1,9 & $1,71 E+11$ & 2,1 & $4,51 E+21$ & 0,0 & $1,46 E+12$ & 0,0 & $6,98 E+13$ & 0,0 \\
\hline & TANDEM 2 & $1,56 E+0$ & 14168,2 & 43,8 & $147,57,59 E+06$ & 2,2 & $6,90 E+11$ & 0,2 & $4,12 E+22$ & 0,0 & $1,95 E+12$ & 0,0 & 1,04 & 0,0 \\
\hline & TANDEM3 & $35,49 \mathrm{E}+$ & 20920,7 & 42,8 & $144,37,69 E+06$ & 0,8 & $7,26 E+11$ & 0,0 & $4,12 E+22$ & 0,0 & $1,96 \mathrm{E}+12$ & 0,0 & $1,04 E+14$ & 0,0 \\
\hline \multirow{5}{*}{$\begin{array}{l}\text { ㄱ. } \\
\text { 위 }\end{array}$} & 1ESRS & $2,24 \mathrm{E}+0$ & 4965,2 & 53,9 & $130,36,35 E+06$ & 3,7 & $5,20 E+09$ & 1,3 & $4,51 E+21$ & 0,0 & $1,89 \mathrm{E}+12$ & 0,0 & $8,52 E+13$ & 0,0 \\
\hline & 2ESRS & $1,95 \mathrm{E}+0$ & 12595,0 & 69,8 & $166,54,80 E+06$ & 0,0 & $4,17 E+07$ & 0,1 & $1,15 E+18$ & 0,0 & $5,13 E+11$ & 0,0 & $1,35 E+13$ & 0,0 \\
\hline & ESRD & $1,26 E+0$ & 7402,6 & 61,5 & $135,05,86 E+06$ & 2,5 & $1,89 E+10$ & 20,8 & $2,77 E+23$ & 0,0 & $2,71 E+12$ & 0,0 & $1,54 E+14$ & 0,0 \\
\hline & TANDEM2 & $1,68 \mathrm{E}+0$ & 4168,2 & 54,6 & $120,56,40 E+06$ & 2,9 & $6,78 \mathrm{E}+10$ & 2,3 & $2,26 E+24$ & 0,0 & $3,41 E+12$ & 0,0 & $2,10 E+14$ & 0,0 \\
\hline & TANDEM3 & $35,90 \mathrm{E}+0$ & 20,7 & 53,2 & $117,36,52 E+06$ & 1,0 & $9,04 \mathrm{E}+10$ & 0,4 & $4,28 E+24$ & 0,0 & $3,61 \mathrm{E}+12$ & 0,0 & $2,27 E+14$ & 0,0 \\
\hline \multirow{5}{*}{$\vec{m}$} & 1ESRS & $2,41 \mathrm{E}+0$ & 4965,2 & 69,1 & $103,84,96 \mathrm{E}+06$ & 5,3 & $4,61 \mathrm{E}+08$ & 15,9 & $4,94 \mathrm{E}+23$ & 0,0 & $3,85 \mathrm{E}+12$ & 0,0 & 2,16 & 0,0 \\
\hline & 2ESRS & $2,09 \mathrm{E}+0$ & 12595,0 & 89,8 & $132,53,45 E+06$ & 0,1 & $3,57 E+06$ & 1,5 & $1,25 E+20$ & 0,0 & $1,38 \mathrm{E}+12$ & 0,0 & $5,12 \mathrm{E}+13$ & 0,0 \\
\hline & ESRD & $1,36 \mathrm{E}+0$ & 7402,6 & 79,6 & $109,34,50 E+06$ & 3,9 & $1,51 \mathrm{E}+09$ & 282,2 & $2,34 \mathrm{E}+25$ & 0,0 & $4,75 E+12$ & 0,0 & $3,16 E+14$ & 0,0 \\
\hline & TANDEM2 & $1,80 E+0$ & 14168,2 & 70,4 & $96,8 \quad 5,04 \mathrm{E}+06$ & 4,2 & $5,81 E+09$ & 30,1 & $2,20 E+26$ & 0,0 & $5,83 E+12$ & 0,0 & $4,12 E+14$ & 0,0 \\
\hline & TANDEM3 & $36,33 \mathrm{E}+0$ & 20920,7 & 68,7 & $94,5 \quad 5,13 E+06$ & 1,4 & $6,39 E+09$ & 5,5 & $2,20 E+26$ & 0,0 & $5,93 E+12$ & 0,0 & $4,17 E+14$ & 0,0 \\
\hline \multirow{5}{*}{$\begin{array}{l}\stackrel{\infty}{\vec{H}} \\
\stackrel{\sigma}{\sigma}\end{array}$} & 1ESRS & $2,58 \mathrm{E}+0$ & 4965,2 & 84,9 & $90,0 \quad 3,86 \mathrm{E}+06$ & 7,6 & $6,71 \mathrm{E}+07$ & 117,6 & $8,32 E+24$ & 0,0 & $5,60 \mathrm{E}+12$ & 0,0 & $3,53 E+14$ & 0,0 \\
\hline & 2ESRS & $2,25 E+0$ & 12595,0 & 110,7 & $115,02,45 E+06$ & 0,1 & $4,97 E+05$ & 11,4 & $2,37 E+21$ & 0,0 & $2,34 \mathrm{E}+12$ & 0,0 & $1,04 E+14$ & 0,0 \\
\hline & ESRD & $1,46 \mathrm{E}+0$ & 7402,6 & 99,0 & $96,3 \quad 3,43 E+06$ & 6,4 & $1,90 E+08$ & 2418,3 & $3,27 E+26$ & 0,0 & $6,37 E+12$ & 0,0 & $4,59 E+14$ & 0,0 \\
\hline & TANDEM2 & $1,94 E+0$ & 14168,2 & 87,2 & $85,3 \quad 3,93 E+06$ & 6,3 & $7,71 E+08$ & 244,0 & $2,72 E+27$ & 0,0 & $7,64 \mathrm{E}+12$ & 0,0 & $5,77 E+14$ & 0,0 \\
\hline & TANDEM3 & $36,80 \mathrm{E}+0$ & 20920,7 & 85,0 & $83,0 \quad 4,01 E+06$ & 2,1 & $8,33 E+08$ & 44,3 & $4,27 E+27$ & 0,0 & $7,91 \mathrm{E}+12$ & 0,0 & $6,02 E+14$ & 0,0 \\
\hline \multirow{6}{*}{$\begin{array}{l}\vec{\sim} \\
\text { ஸे }\end{array}$} & 1ESRS & $2,78 \mathrm{E}+0$ & 4965,2 & 98,5 & 93,3 3,12E+06 & 10,6 & $1,45 \mathrm{E}+07$ & 584,7 & $4,29 E+24$ & 0,0 & $5,14 \mathrm{E}+12$ & 0,0 & $3,16 E+14$ & 0,0 \\
\hline & 2ESRS & $2,41 E+0$ & 12595,0 & 128,9 & $120,01,82 E+06$ & 0,2 & $1,03 E+05$ & 59,1 & $9,77 E+20$ & 0,0 & $2,01 E+12$ & 0,0 & $8,44 \mathrm{E}+13$ & 0,0 \\
\hline & ESRD & $1,56 \mathrm{E}+0$ & 7402,6 & 116,2 & $101,82,73 E+06$ & 10,1 & $3,61 \mathrm{E}+071$ & 13725,6 & $1,01 E+26$ & 0,0 & $5,60 E+12$ & 0,0 & $3,90 E+14$ & 0,0 \\
\hline & TANDEM2 & $2,08 E+0$ & 14168,2 & 101,6 & $89,33,20 E+06$ & 9,0 & $1,60 E+08$ & 1268,5 & $1,13 E+27$ & 0,0 & $6,96 \mathrm{E}+12$ & 0,0 & $5,14 \mathrm{E}+14$ & 0,0 \\
\hline & TANDEM3 & $37,31 \mathrm{E}+0$ & 0920,7 & 98,9 & $86,8 \quad 3,28 \mathrm{E}+06$ & 2,9 & $1,78 \mathrm{E}+08$ & 225,4 & $1,75 \mathrm{E}+27$ & 0,0 & $7,24 \mathrm{E}+12$ & 0,0 & $5,39 E+14$ & 0,0 \\
\hline & & & & & & 99,7 & & 19062,2 & & 0,0 & & 0,0 & & 0,0 \\
\hline
\end{tabular}

OBS.: Nível de Confiança aplicado aos modelos SAPEM (2014) e AUSTROADS (2012) foi de 50\%.

(1) Valores utilizados no cálculo: $S F=1,36 ; \varepsilon_{b}=120$ (material $C 2$ ); $c=7,06 ; d=7,86$.

(2) $R F=11,743$.

(3) $B_{c 3}=1,0259 ; B_{c 4}=1,1368 ; R_{T, c d}=0,672 \mathrm{MPa} ; R_{T, f}=0,941 \mathrm{MPa}$.

(4) $B_{c 1}=1,0645 ; B_{c 2}=0,9003 ; R_{T, c d}=0,672 \mathrm{MPa} ; R_{T, f}=0,941 \mathrm{MPa}$.

(5) $R_{T, c d}=0,672 \mathrm{MPa} ; R_{T, f}=0,941 \mathrm{MPa}$.

\subsection{Ajuste de modelos de fadiga com deformação de tração para BGTC}

Conforme observado no item 5.2, para a análise de dano acumulado, os modelos que utilizam a deformação específica de tração na fibra inferior da camada cimentada, como critério de ruptura por fadiga, parecem ser mais adequados quando se utiliza a redução da rigidez da camada ao longo do tempo. Portanto, propôs-se a utilização do modelo do SAPEM (2014) ao nível de confiança de 50\% sem a necessidade de ajustes, já que convergiu ao dano muito próximo a 100\% dentro do período de análise. 0 modelo do SAPEM (2014) tem a seguinte representação:

$$
N_{f 1}=S F \cdot 10^{7,06\left(1-\frac{\varepsilon_{t}}{7,86 \cdot \varepsilon_{b}}\right)}
$$


em que $\quad N_{f 1}$ : número de repetições de eixo para a ruptura por fadiga em camadas cimentadas;

$S F$ : fator de correção para propagação da trinca em função da espessura da camada (SAPEM, 2014);

$\varepsilon_{t}$ : deformação específica de tração na fibra inferior da camada [microstrain];

$\varepsilon_{b}$ : deformação de ruptura por tração [microstrain] (SAPEM, 2014).

0 gráfico da Figura 5 a representa a variação do $N_{f 1}$ em função do $\varepsilon_{t}$ para o modelo do SAPEM (2014) e a Figura 6a o gráfico de dispersão entre valores de tráfego observados $\left(N_{o}\right)$ e estimados pelo modelo $\left(N_{e}\right)$. Entende-se por valores observados $\left(N_{o}\right)$ o tráfego contabilizado no trecho monitorado, por tipo de eixo e carga, responsável por gerar uma determinada deformação no pavimento sob as condições estruturais medidas na data da análise.

O modelo tem evolução exponencial e obteve-se boa simetria entre valores observados e estimados, ou seja, baixos resíduos. Na Figura 7a observa-se o ajuste da curva de evolução do módulo elástico da camada $\left(E_{D 1}\right)$ em função do dano acumulado calculado por esse modelo. A estimativa do módulo da camada cimentada em função do dano acumulado pode ser obtida da seguinte forma:

$$
E_{D 1}=E_{\text {min }}+\frac{\left(E_{\text {máx }}+E_{\text {min }}\right)}{\left[1+e^{\left(4,155+4,557 \times \log \left(D_{1}\right)\right)}\right]}
$$

em que $\quad E_{D 1}$ : módulo elástico da camada no nível de dano $D_{1}[\mathrm{MPa}] ;$

$E_{\text {mín }}$ : módulo da camada após $D_{1}$ igual a $100 \%$ [MPa];

$E_{\text {máx }}$ : módulo da camada para a camada intacta [MPa];

$D_{1}$ : nível de dano em forma decimal.

Devido o modelo da AUSTROADS (2012) ter apresentado dano acumulado superior a $100 \%$ no período de análise, o mesmo passou por um ajuste fixando a vida de fadiga ao $21^{\circ}$ mês. Este ajuste objetivou calcular os novos coeficientes do modelo para que a ruptura da camada coincidisse com as observações de campo, não sendo objetivo calibrar a forma de evolução do dano. 0 modelo da AUSTROADS ajustado neste trabalho tem a seguinte representação:

$$
N_{f 2}=R F \cdot\left(\frac{17446,4 / E^{0,804}+295,369}{\varepsilon_{t}}\right)^{12}
$$

em que $N_{f 2}$ : número de repetições de eixo para a ruptura por fadiga em camadas cimentadas;

$E$ : módulo elástico do material cimentado [MPa];

$\varepsilon_{t}$ : deformação específica de tração na fibra inferior da camada [microstrain];

$R F$ : fator relacionado ao nível de confiança para a fadiga de materiais cimentado (JAMESON, 2014).

A estimativa do módulo da camada cimentada em função do dano acumulado gerado pelo modelo da equação 11 pode ser obtida da seguinte forma:

$$
E_{D 2}=E_{\text {min }}+\frac{\left(E_{\text {máx }}+E_{\text {min }}\right)}{\left[1+e^{\left(6,152+1,411 \log \left(D_{2}\right)\right)}\right]}
$$


em que $E_{D 2}$ : módulo elástico da camada no nível de dano $D_{2}[\mathrm{MPa}] ;$

$D_{2}$ : nível de dano em forma decimal.

0 gráfico da Figura $5 b$ representa a variação do $N_{f 2}$ em função do $\varepsilon_{t}$ para o modelo ajustado da AUTROADS, a Figura 6b o gráfico de dispersão entre valores de tráfego observados $\left(N_{o}\right)$ e estimados pelo modelo $\left(N_{e}\right)$ e na Figura $7 \mathrm{~b}$ observa-se o ajuste da curva de evolução do $E_{D 2}$ em função do dano acumulado calculado por esse modelo. 0 modelo do AUTROADS tem um ajuste em potência, mas com boa simetria entre valores observados e estimados, também com baixos resíduos.

A escala do $N_{f}$ na Figura $5 b$ teve representação logarítmica para tornar possível a observação da redução acentuada desta variável com o aumento do $\varepsilon_{t}$. Este modelo (Equação 11) é mais sensível ao aumento da deformação específica de tração que o modelo da Equação 09, com o acúmulo de danos concentrando-se em deformações superiores a $100 \times 10^{-6} \mathrm{~m} / \mathrm{m}$. Isto fica mais evidente quando se analisa a Figura $7 \mathrm{~b}$, onde a evolução de danos é acentuada após a camada atingir o módulo de resiliência entre $1.200 \mathrm{MPa}$ e $800 \mathrm{MPa}$, já após o aparecimento de microfissuras, representando a fase de trincamento avançado. Enquanto isso, a evolução do dano acumulado na Figura 7a é mais suave, acompanhando a redução de rigidez da camada até o módulo de resiliência em torno de $1.200 \mathrm{MPa}$ (dano de 35\%), e evoluindo acentuadamente até atingir $800 \mathrm{MPa}$ na fase de trincamento avançado (65\% do dano).

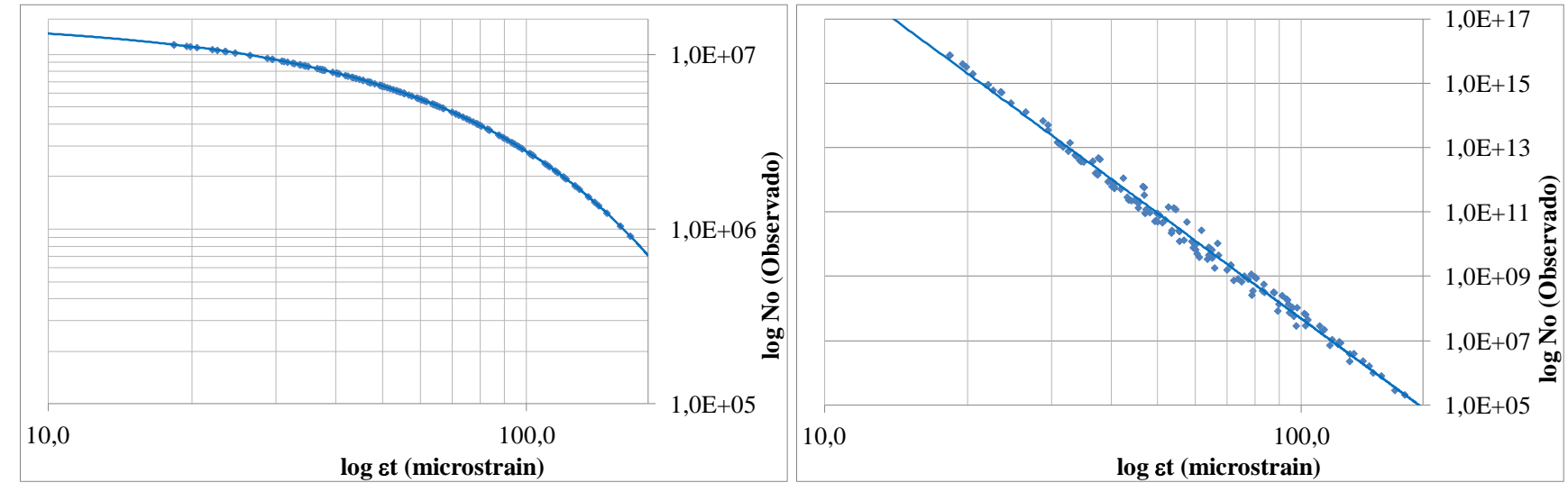

(a) (b)

Figure 6. (a) Curva do modelo do SAPEM (2014); (b) Curva de Ajuste do modelo do AUSTROADS

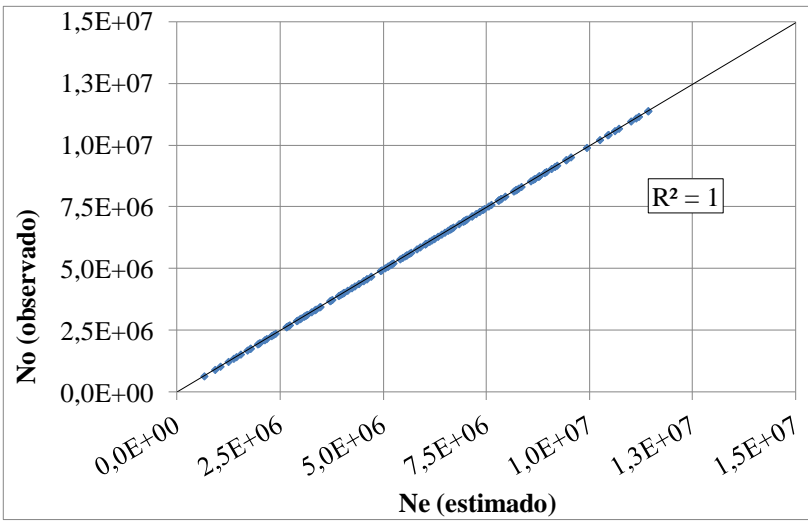

(a)

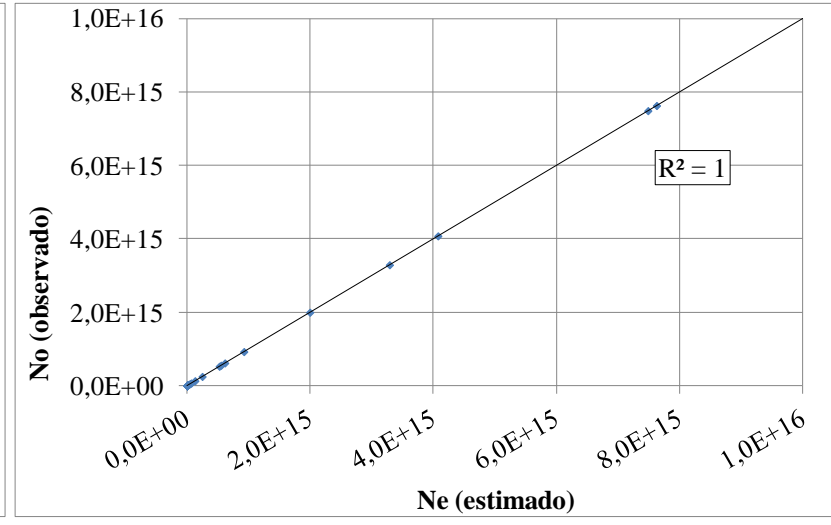

(b)

Figure 7. (a) $N_{o}$ (observado) $\times N_{e}$ (estimado) com modelo do SAPEM (2014); (b) $N_{o}$ (observado) $\times N_{e}$ (estimado) com modelo ajustado da AUSTROADS 


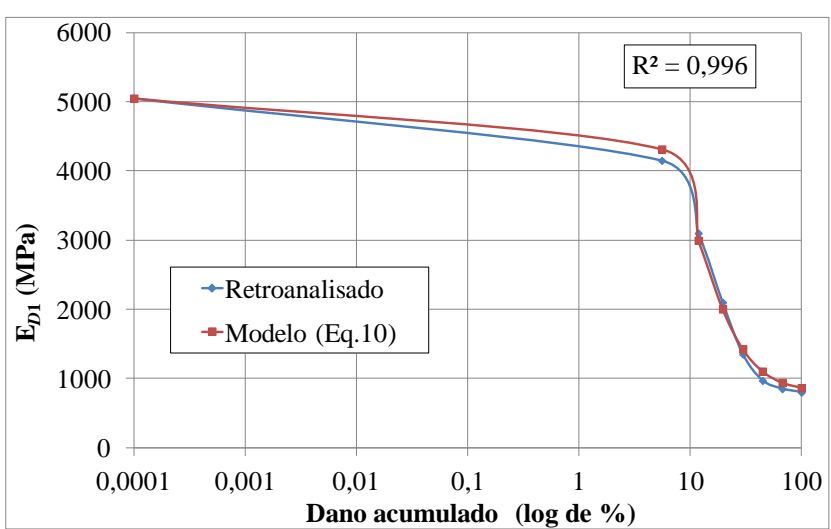

(a)

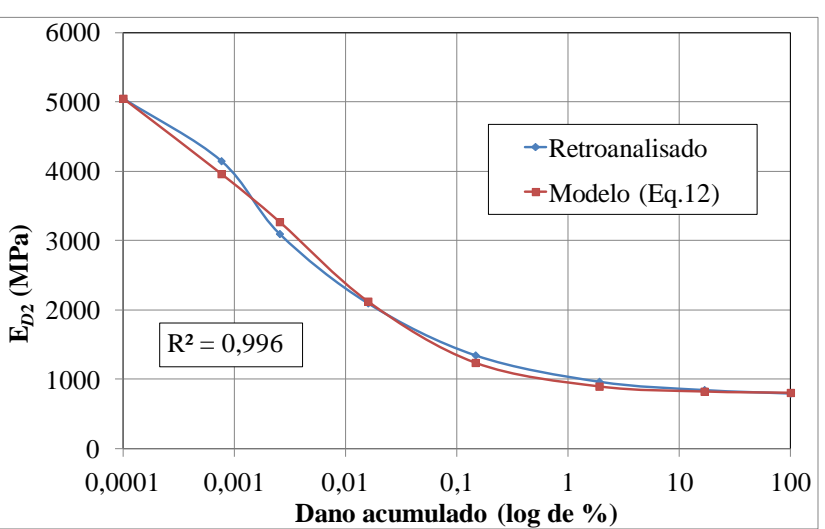

(b)

Figure 8. (a) Evolução do $E_{D 1}$ estimado e real com o dano; (b) Evolução do $E_{D 2}$ estimado e real com o dano

\section{CONCLUSÕES}

Neste trabalho foi proposta uma análise crítica e um ajuste preliminar de modelos de previsão de dano por fadiga em bases cimentadas do tipo BGTC, utilizando dados de um trecho monitorado de pavimento asfáltico semirrígido na BR-101/SE. A análise de fadiga foi realizada pelo cálculo incremental de danos, levando-se em consideração variações nas características de rigidez das camadas do pavimento a cada período de três meses.

Observando-se a evolução do módulo de resiliência retroanalisado da camada de BGTC e seus pontos de inflexão ao longo do tempo, puderam-se definir as fases que caracterizam o trincamento por retração, o microtrincamento devido à fadiga e o trincamento avançado até que o trincamento atingisse o topo da camada.

A vida de fadiga foi definida quando o módulo de resiliência da BGTC atingiu $800 \mathrm{MPa}$, aos 21 meses do pavimento em serviço. Na análise incremental de danos, os modelos da AASHTO (2004), PCA (1984) e de Balbo (1993) resultaram em uma vida de fadiga crescente ao longo do tempo, devido os mesmos utilizarem a tensão de tração como critério de ruptura. Como na análise temporal o módulo de resiliência da BGTC reduziu, as tensões internas na camada também reduziram, impossibilitando uma convergência matemática ao real desempenho do pavimento quando utilizando este critério. Certamente, o estudo de dano considerando o método do número equivalente acumulado de repetições de um eixo padrão forneceria resultados diferentes para esses modelos. Contudo, necessita-se de calibração dos modelos de equivalência de carga para cada tipo de eixo.

O modelo da AUSTROADS (2012), utilizando o critério de deformação específica de tração, convergiu a uma vida de fadiga menor que a observada em campo, subestimando em grande número o tráfego que levaria à ruptura da camada. Por outro lado, o modelo do SAPEM (2014) a um nível de confiança de 50\%, que também utiliza o critério de deformação específica de tração, descreveu exatamente o comportamento de fadiga da BGTC no trecho monitorado, dispensando o procedimento de ajuste.

O modelo da AUSTROADS já ajustado apresentou uma evolução do dano em forma potencial, sendo muito sensível ao aumento da deformação específica de tração. Quase $100 \%$ do dano à camada aconteceria quando à mesma estivesse no intervalo de módulo de resiliência entre $1.200 \mathrm{MPa}$ a $800 \mathrm{MPa}$.

0 modelo do SAPEM apresentou uma evolução exponencial do dano e de forma mais suavizada que o modelo ajustado da AUSTROADS. Cerca de 35\% do incremento de dano ocorreu até que o módulo de resiliência atingisse $1.200 \mathrm{MPa}$, tendo um incremento de danos um pouco mais acentuado (cerca de 65\%) até atingir $800 \mathrm{MPa}$ na fase de trincamento avançado.

0 critério da deformação específica de tração pareceu, portanto, mais adequado para a análise de dano acumulado, sobretudo devido à redução do módulo de resiliência da BGTC ao longo do tempo, o 
que provoca um aumento nos valores de deformações.

Embora se entenda que a contribuição ao incremento de danos ocorra em cada uma das fases que caracterizam as camadas cimentadas (trincamento por retração, microtrincamento por fadiga e trincamento avançado por fadiga), conforme elucidado pelo modelo do SAPEM, talvez seja interessante o uso do modelo ajustado da AUSTROADS quando as deformações específicas de tração iniciais calculadas para a camada cimentada sejam na ordem de 100 microstrains.

Os modelos do SAPEM e AUSTROADS aqui estudados representam um ponto de partida para um estudo avançado, envolvendo uma calibração dos mesmos com uma amostragem maior, conforme é realizado na própria África do Sul e Austrália há anos. Contudo, os mesmos podem ter aplicabilidade adequada para pavimentos executados com características semelhantes de granulometria e de dosagem da BGTC utilizada nesta pesquisa.

\section{AGRADECIMENTOS}

À Superintendência Regional do Departamento Nacional de Infraestrutura de Transportes no estado de Sergipe pela cessão do trecho monitorado e pelo apoio técnico e logístico para a realização desta pesquisa.

\section{REFERÊNCIAS}

AASHTO (2004). Guide for mechanistic-empirical design of new and rehabilitated pavement structures. NCHRP Project 1-37A. American Association of State Highway and Transportation Officials \& Federal Highway Administration. National Cooperative Highway Research Program. Transportation Research Board. Washington, DC.: National Research Council. Disponível em: <http://onlinepubs.trb.org/onlinepubs/archive/mepdg/home.htm>.

Associação Brasileira de Normas Técnicas (2007). NBR 5739:2007: concreto: ensaios de compressão de corpos-de-prova cilíndricos. Rio de Janeiro: ABNT.

AUSTROADS (2008). The development and evaluation of protocols for the laboratory characterisation of cemented materials. AP-T101/08. Sydney: Austroads .

AUSTROADS (2012). Guide to pavement technology part 2: pavement structural design. AGPT02-12. Sydney: Austroads,

Balbo, J. T (1993). Estudo das propriedades mecânicas das misturas de brita e cimento e sua aplicação aos pavimentos semirígidos. Tese (Doutorado). EPUSP, Universidade de São Paulo, São Paulo.

Chakrabarti, S. e Kodikara, J. (2003). Basaltic Crushed Rock Stabilized with Cementitious Additives: Compressive Strength and Stiffness, Drying Shrinkage, and Capillary Flow Characteristics. Transportation Research Record, n. 1819, p. 18-26. DOI: 10.3141/1819b-03.

Chen, D.; Scullion, T.; Lee, T. e Bilyeu, J. (2008). Results from a forensic investigation of a failed cement treated base. Journal of Performance of Constructed Facilities, v. 22, n. 3, p. 143-153. DOI: 10.1061/(ASCE)0887-3828(2008)22:3(143).

CONTRAN (1999). Resolução № 102, de 31 de agosto de 1999: Dispõe sobre a tolerância máxima de peso bruto de veículos. Brasília: Conselho Nacional de Trânsito,

Djakfar, L. e Roberts, F. (1999). Performance Comparison of Base Materials Under Accelerated Loading. Transportation Research Record, n. 1655, p. 211-218. DOI: 10.3141/1655-27.

DNER (1981). IPR 667/2: método de projeto de pavimentos flexíveis. Rio de Janeiro: Departamento Nacional de Estradas de Rodagem,

DNER (1994). DNER-PRO 269/94: projeto de restauração de pavimentos flexíveis: TECNAPAV. Rio de Janeiro: Departamento Nacional de Estradas de Rodagem,

DNIT (2010a). DNIT 134/2010- ME pavimentação: solos: determinação do módulo de resiliência: método de ensaio. Rio de Janeiro: Departamento Nacional de Infraestrutura de Transportes,

DNIT (2010b). DNIT 135/2010 - ME Pavimentação asfáltica: misturas asfálticas: determinação do módulo de resiliência: método de ensaio. Rio de Janeiro: Departamento Nacional de Infraestrutura de Transportes,

Franco, F.A. (2007). Método de dimensionamento mecanístico-empírico de pavimentos asfálticos: Sispav. Tese (Doutorado)- Universidade Federal do Rio de Janeiro, Rio de Janeiro.

Guthrie, W.; Crane, R. e Eggett, D. (2009). Statistical comparison of mechanistic-empirical models for predicting fatigue life of cement-treated base layers over weak subgrades. Cold Regions Engineering 2009, American Society of Civil Engineers (ASCE), p. 407-416. DOI: 10.1061/41072(359)40.

Huang, Y. H. (2004). Pavement analysis and design. $2^{\text {nd }}$. ed. New Jersey, USA: Prentice Hall. 785 p.

Jameson, G. (2014). Improve fatigue characterization of cemented materials. In: ARRB CONFERENCE - RESEARCH DRIVING EFFICIENCY, 26.,2014. Anais... Sydney, Australia.

NAASRA (1987). Pavement design, a guide to the structural design of road pavements. Sydney: National Association of Australian State Road Authorities,

Park, S. W. e Y. R. Kim (1997). Temperature Correction of Backcalculated Moduli and Deflections Using Linear Viscoelasticity and Time-Temperature Superposition. Transportation Research Record, v. 1570, p. 108-117. DOI: 10.3141/1570-13.

PCA (1984). Thickness design for concrete highway and street pavements. Illinois: Portland Cement Association. 
SAPEM (2014). South african pavement engineering manual. The South African National Roads Agency Ltd.

Scullion, T., Uzan, J., Hilbrich, S. e Chen, P. (2007). Thickness design systems for pavements containing soil cement bases. PCA R\&D Serial n. 2863. Skokie: Portland Cement Association, , Ill.

Theyse, H L; Beer, M. e Rust, F C. (1996). Overview of the south african mechanistic pavement design analysis method. Transportation Research Record (TRB), v. 1539, p. 6-17. DOI: 10.3141/1539-02.

Yeo, Yang Sheng. (2011). Characterisation of cement treated crushed rock basecourse for western australian roads. Thesis (Doctor of Philosophy) - Curtin University. Bentley, Australia.

Yoder, E.J. e M.W. Witczak (1975). Principles of pavement design. 2nd. ed., New York, USA: John Wiley \& Sons. 736 p. 